\title{
Serological Evidence and Risk Factors of Hepatitis A Virus among Blood Donors in 3 Tertiary Hospitals in Sokoto, Nigeria
}

Ngwoke, Chinedu Clinton ${ }^{1}$, Mohammed, Kabiru ${ }^{1}$, Okechukwu, Chisom Emmanuel, Abdullahi, Idris Nasir ${ }^{2}$, Ikeh, Emeka Eugene ${ }^{1}$, Spencer, Thompson HI ${ }^{1}$

${ }^{1}$ Department of Medical Microbiology, Faculty of Medical Laboratory Science, Usmanu Danfodiyo University, Sokoto, Nigeria.

${ }^{2}$ Department of Medical Laboratory Science, College of Medical Sciences,

Ahmadu Bello University, Zaria, Nigeria.

Corresponding Author

Abdullahi, Idris Nasir

Mobile:

$+2348022851352$

E mail: eedris888@yahoo.com inabdullahi@abu.edu. $n g$

Key words: Hepatitis A, Serosurvey, Immunoglobulin, Safe blood
Background and study aim: Globally, Hepatitis-A Virus (HAV) is a major etiology of acute hepatitis. Though, enterically transmitted, there is evidence HAV being transmitted through blood transfusion. The presence of HAV antibodies may indicate infectious threat to blood transfusion safety. In view of these, the present study was aimed to determine the seroprevalence and associated risk factors of HAV among blood donors in three tertiary Hospitals in Sokoto State, Nigeria.

Materials and Methods: Blood samples were collected from one hundred and sixty eight (168) blood donors $>20$ years. Sera from these samples were investigated for anti-HAV specific IgG and IgM antibodies using a commercial enzyme immunosorbent assay (ELISA) Kits. Structured questionnaires were used to access sociodemographic variables of subjects.
Results: Seroprevalence of HAV- specific $\mathrm{IgG}$ and $\mathrm{IgM}$ were $86.3 .1 \%$ and $0.0 \%$, respectively. Of 168 blood donors, 145 had previous exposure to HAV $[\operatorname{IgG}(+)$ $\operatorname{IgM}(-)$, and none had recent infection [IgG (-) $\operatorname{IgM}(+)], 23$ were susceptible to $\mathrm{HAV}[\operatorname{IgG}(-) \operatorname{IgM}(-)$. There was no significant association between seroprevalence and any of the risk factors and sociodemographic variables studied $(\mathrm{p}>0.05)$. Findings from this study revealed that larger proportion of blood donors are already immune to HAV infection, while none of them had active HAV infection.

Conclusion: The high prevalence of Hepatitis A antibodies among the studied subject reflects a high HAV transmission rate in this area. Hence, determination of HAV should be taken into consideration before blood transfusion.

\section{INTRODUCTION}

Hepatitis A virus (HAV), belongs to Picornaviridae family. It's a naked single-stranded RNA virus [1]. HAV replicates and multplies in liver cells and interferes with liver function, activating an immune response that causes hepatitis. HAV has fecal-oral route of transmission through direct contact with an infectious person and ingestion of contaminated food/water [1].

Hepatitis A virus (HAV) is endemic in many developing countries, where the prevalence can approach $100 \%$ in children by 5 years of age [2]. It is responsible for all $75 \%$ of viral hepatitis in the world. The disease has global distribution and is more common in areas with low levels of socioeconomic development. Incidence is elevated in developing countries and the majority of these populations will become infected before the age of 10 years [3].

The seroprevalence of HAV is low in developed countries and the greater part of those populations will remain susceptible to infection even at advanced ages [4]. Persons infected shed HAV in their feces 7-10 weeks before the onset of clinical symptoms. HAV 
concentration in feces is highest during the prodromal phase. For those who develop symptoms, the concentration is usually very low by the time jaundice appears and undetectable before symptoms abate [4].

Epidemiologically, predictors of HAV infection include poor household condition, low socioeconomic status, residence in rural community, poor and inadequate water sources, and limited access to environmental sanitation facilities [5]. Several additional high-risk population groups have been identified, including those who travel or emigrate from a non-endemic region to an endemic region and those who work in certain high-risk occupations, such as some daycare employees [6].

The disease spreads most quickly in highly populated areas with poor sanitation infrastructure and a shortage of water. Infections occur most commonly among children under the age of ten, and in most cases, the patients remain asymptomatic [7]. In most of the developed world, HAV is more likely to be contracted by older adolescents or adults [7]. In some cases, HAV infection has significantly increased the age at contraction. Delay in HAV exposure has made large population of adolescents and adults susceptible and of high risk of HAV and could lead to outbreaks of hepatitis A [8]. In view of this, it's important to consider implementing vaccination programs that target to certain populations at higher risk of infection [9].

There is paucity of data on the prevalence of HAV in Sokoto State, North Western Nigeria. This prospective cross-sectional study was designed to determine the seroprevalence and risk factors of HAV among blood donors in three tertiary Hospitals in Sokoto State, Nigeria.

\section{MATERIALS AND METHODS}

\section{Study design and Site}

This cross-sectional study was carried on one hundred and sixty eight (168) blood donors that attended Maryam Abacha Hospital, Specialist Hospital and Women-children Welfare clinic in Sokoto State, Northwestern Nigeria.

\section{Selection criteria}

Inclusion criteria

1. Those who donate blood voluntarily
2. Individuals who were apparently healthy in the last 21 days

3. Those who gave consent to participate in the study

\section{Exclusion criteria}

1. Those who do not consent to voluntarily participate in the study

2. Non blood donors

3. Those who are willing but not healthy in the last 21 days

\section{Questionnaire}

Structured open ended questionnaires were prepared and administered on the spot to each participant. The participants were asked about their socio-demographic details including identification number, sex, age, ethnicity, educational qualification, occupation and marital status. Information was also asked about the place of residence, availability of toilet facilities, and availability of good drinking water, good waste disposal facility.

\section{Sample Collection}

$3 \mathrm{~mL}$ of blood sample was collected from individual participant using standard venipuncture phlebotomy. The sample was carefully and gently dispensed into a sterile plain sample container. The tubes were labelled appropriately with participants' identification number.

Sera from the blood samples were separated by allowing the blood to clot at room temperature then by centrifugation at $2500 \mathrm{rpm}$ for 10 minutes. Thereafter transferred into serum aliquot container and stored at $-20^{\prime} \mathrm{C}$ pending laboratory analysis.

\section{Serum HAV Enzyme Linked Immunosorbent Assay (IgM and IgG ELISA)}

The serum samples were tested for the presence of HAV-IgM level using the sandwich Enzyme Linked Immunosorbent Assay (ELISA) kit produced by Melsin Medical Co., Limited. Jilin Province, China. The Melsin HAV-IgM and IgG ELISA kits have Assay sensitivity of $99.75 \%$ and Specificity of $99.9 \%$. Analyses were done based on kits manufacture's instruction.

HAV-IgM and IgG ELISA are solid phase, twostep incubation, antibody capture ELISA assay in which, polystyrene microwell strips are precoated with antibodies directed to IgM and $\operatorname{IgG}$ proteins (anti-ì chain). The subjects' sera were added. During the 1st incubation, any antibodies will be captured in the wells. After washing out 
all the other components of the sample, the specific HAV antibody will be captured on the solid phase, and was detected by the addition of HAV antigens conjugated to horseradish peroxidise (HRP-Conjugate). During the second incubation, the HRP-conjugated antigens will specifically react only with the HAV antibodies. After washing to remove unbound HRP-conjugate, a tetramethylbenzidine (TMB) chromogen solution was added to the wells. In presence of the (anti-i)-(HAVantibody)-(antigen-HRP) immunocomplex, the colorless Chromogens were hydrolyzed by the bound HRP conjugate to a blue-colored product. The blue color turns yellow after stopping the reaction with sulfuric acid. The amount of color intensity can be measured and is proportional to the amount of antibody captured in the wells, and to the sample respectively. Wells containing samples negative for $\mathrm{HAV}$-antibodies remain colorless.

\section{Sample size}

The sample size was determined using prevalence rate demonstrated by Ramezani et al [10]. This was 150 . Hence the minimum calculated sample size was $\mathrm{N}=150$

Attrition rate $=(150 \mathrm{X} 0.2)=30 . \mathrm{N}=30+150=180$

\section{Data collection}

Questionnaires were used to collect sociodemographic data, such as gender, age, marital status, occupation, number of Household members, availability of hygienic toilet facility and good water supply.

\section{Sample collection}

2 milliliters of blood sample was collected from individual participant using standard venepunture phlebotomy. The sample was carefully and gently dispense into a sterile plain sample container. The tube was labeled appropriately with participants' identification number. Sera from the blood samples were separated by allowing the blood to clot at room temperature then by centrifugation at $2500 \mathrm{rpm}$ for 10 minutes. Thereafter transferred into serum aliquot container and stored at $-20^{\prime} \mathrm{C}$ pending laboratory analysis.

\section{Statistical analysis}

Data obtained from ELISA and questionnaire were presented in tabular and graphical forms. Pearson Chi square test at a 95\% confidence interval and a significance level of 0.05 was used to determine the association between sociodemographic data and seroprevalence rates using Statistical Package for Social Sciences (SPSS version 23, California, USA).

\section{RESULTS}

One hundred and sixty-eight (168) blood donors participated in the study. All participants were within the age range of 20-45 years old. The results of the ELISA were categorized into 3 serological responses. The first group was immune to $\mathrm{HAV}[\operatorname{IgG}(+)$ and $\operatorname{IgM}(-)]$, which consisted of 145 Blood donors. In the second group, there was none with only one recent infection $[\operatorname{IgG}(+)$ and $\operatorname{IgM}(-)]$. In the third group there were 23 women who were susceptible to HAV infection [IgG (-) but had $\operatorname{IgM}(-)]$. Thus, anti- HAV IgG seropositivity was $86.3 \%$ and anti-HAV IgM seropositivity was $0.0 \%$ (Table 1). Table 2a shows the distribution of HAV- specific IgG and IgM seropositivity across ages of blood donors. HAV IgG seropositivity was mostly observed among those age range (2030 ) years; (31-40) years had $86.2 \%$ while above 41 years $(76 \%)$. Table 3 shows the distribution of Human HAV- specific IgG seropositivity across occupation, number of household members, availability of good toilet facility, and availability of good water supply. There was no significant association between seroprevalence and any of the risk factors and sociodemographic variables studied $(\mathrm{p}>0.05)$. 
Table (1) : Summary of anti-HAV IgM and IgG antibodies among blood donors and their corresponding diagnostic interpretation

\begin{tabular}{|c|l|c|c|}
\hline S/No & Antibodies reactivity & Number of subjects (\%) & Interpretation \\
\hline 1 & HAV IgG (+ve) and IgM (-ve) & $145(86.3)$ & Past infection \\
\hline 2 & HAV IgG (-ve) and IgM (+ve) & $0(0.0)$ & Recent infection \\
\hline 3 & HAV IgG (-ve) and IgM (-ve) & $23(13.6)$ & Susceptible \\
\hline
\end{tabular}

Table (2) : Distribution of Hepatitis A Virus IgG by sociodemographic variables of subjects

\begin{tabular}{|c|c|c|c|c|c|}
\hline \multicolumn{2}{|c|}{ Variables } & IgG Positive & IgG Negative & No. of Subjects tested & $P$-value \\
\hline \multicolumn{2}{|c|}{ Gender } & & & & 0.830 \\
\hline \multicolumn{2}{|c|}{ Male } & $132(86.8)$ & $20(86.8)$ & $152(100)$ & \\
\hline \multicolumn{2}{|c|}{ Female } & $13(81)$ & $2(9)$ & $16(100)$ & \\
\hline \multicolumn{2}{|l|}{$\overline{\text { Age }}$} & & & & 0.5694 \\
\hline 20 & -30 & $79(88.7)$ & $10(11.3)$ & $89(100)$ & \\
\hline 31 & -40 & $50(86.2)$ & $8(13.8)$ & $58(100)$ & \\
\hline 41 & $>$ & $16(76)$ & $4(24)$ & $20(100)$ & \\
\hline \multicolumn{2}{|c|}{ Marital status } & & & & 0.461 \\
\hline \multicolumn{2}{|c|}{ Married } & $117(86.6)$ & $18(13.4)$ & 135 & \\
\hline \multicolumn{2}{|c|}{ Single } & $28(84)$ & $4(16)$ & 33 & \\
\hline
\end{tabular}

Table (3) : Risk factors of Hepatitis A Virus IgG of blood donors

\begin{tabular}{|c|c|c|c|c|}
\hline Variables & IgG Positive (\%) & $\begin{array}{c}\text { IgG Negative } \\
(\%)\end{array}$ & $\begin{array}{c}\text { No. of Subjects } \\
\text { tested }(\%)\end{array}$ & P-value \\
\hline Occupation & & & & 0.568 \\
\hline Trader & $26(86.6)$ & $11(13.3)$ & 31 & \\
\hline Farmer & $48(82.7)$ & $4(17.8)$ & 52 & \\
\hline Civil Servant & $22(84.6)$ & $1(15.4)$ & 23 & \\
\hline Artisan & $13(92.8)$ & $3(8.2)$ & 16 & \\
\hline Student & $36(92.3)$ & $23(8.7)$ & 59 & \\
\hline NHHM & & & & 0.639 \\
\hline $1-5$ & $49(87.2)$ & $7(12.8)$ & 56 & \\
\hline $6-10$ & $79(85.1)$ & $15(14.9)$ & 94 & \\
\hline $11-15$ & $12(92.3)$ & $1(7.7)$ & 13 & \\
\hline $16-20$ & $5(100)$ & $0(0)$ & 5 & \\
\hline AVHTF & & & & 0.158 \\
\hline Yes & $42(75.9)$ & $10(14.1)$ & 52 & \\
\hline No & $103(92)$ & $13(8)$ & 116 & \\
\hline AVGWS & & & & 0.640 \\
\hline Yes & $46(85)$ & $8(15)$ & 54 & \\
\hline No & $99(87)$ & $15(13)$ & 114 & \\
\hline
\end{tabular}

AVHTF=Availability of hygienic toilet facility AVGWS= Availability of good water supply, NHHM= Number of Household members 


\section{DISCUSSION}

The findings of this study revealed that $86.3 \%$ of the blood donors had anti- HAV IgG with no corresponding anti-HAV IgM antibodies. Development of IgG antibodies to HAV indicates that these blood donors had previous infection with HAV in their life time. This seroprevalence was higher than that reported by Ikobah et al. [11] with 55.5\% in Cross River state and Ayoola et al. [12] with $42.5 \%$ in Oyo state. However it is lower than that reported by David et al. [13] with 97.85\% in Osun state and Ramezani et al. [10] in central Iran with $90 \%$ prevalence. The reason for this high prevalence may be as a result low levels of socioeconomic development, no availability of good toilet facility and good water supply in Sokoto metropolis.

Incidence is elevated in developing countries and the majority of these populations will become infected before the age of 10 years [4]. This may reflect the ignorance of the disease and low hygienic and cultural practices, which can increase HAV infection transmission in low income countries. However, this study agrees with Hadler [14], who reported that prevalence of HAV infection is not the same in different parts of the world (varies between 15\% and 100\%), and depends on geographic area, sanitary levels and socioeconomic conditions. This disparity in prevalence could be due to difference in duration of study, the location of the study, level of hygiene, water supply, vaccination, endemicity of the virus, the study subjects and use of different test system with varying sensitivity.

There was an exponential decrease in prevalence HAV based on age distribution. Age group of 20-30 years has a prevalence of $88.7 \%$, while 3040 years had $8.2 \%$, above 41 years, $76.0 \%$. This may be due to the high activities of this age group and the facts that this age group has the highest frequency. Our finding is in accordance with that of Okara et al. [15], which showed a highest prevalence among age group 20-40 years, but contrary to that of, Jacobsen and Wiersma [16] and Colak et al. [17] which showed that those positive for anti-HAV antibody were older than those without the infection. Age range between 20-30 years should be giving priority, since this represents greater risk of outbreaks in near future, and analyzing the cost effectiveness of vaccination programs might be worthwhile.

Gender distribution of HAV showed that a prevalence $88.7 \%$ amongst male blood donors and $86.6 \%$ amongst females. This could be attributed to the number of male to females in the study. This agrees with Ikobah et al. [11] and Gomes et al. [18] which showed that prevalence is higher in male than female. This could also be ascribed to the fact the female are more hygienic than male counterparts as this infection can be easily transmitted through fecal-oral route, by close contact with infected person, and contaminated food and water and even blood and blood products.

This present study recorded $100 \%$ prevalence for those with household size of 16-20, then household size of 11-15 with $92 \%$ while those 15 members recorded the lowest with $81 \%$. This findings corroborate with that of Jacobsen and Jacobsen and Koopman [8]. This shows that larger household size and crowding are part of the predictors of Hepatitis A virus infection.

\section{CONCLUSION}

Findings from this study indicated that a large number of the blood donors are already immune to HAV infection, while none of them had active HAV infection. The high prevalence of Hepatitis A antibodies among the studied subject reflects a high HAV transmission rate in this area. Hence, determination of HAV should be taken into consideration before blood transfusion.

Ethical Consideration and Informed Consent Ethical approval was obtained from the Ethical and Human research committee of the Ministry of Health, Sokoto state. Informed consent was also obtained from all participating subjects in accordance with the standards of human experimentation and with the Helsinki Declaration of 1975, as revised in 2000. This was done via an informed consent forms duly completed by all the subjects.

\section{Conflict of interest \\ None}

Funding:

None

\section{REFERENCES}

1. Cuthbert JA. Hepatitis A: old and new. Clin Microbiol Rev; 2001; 14: 36-58.

2. Poovorawan Y, Chatchatee P, Chongsrisawat V. Epidemiology and prophylaxis of viral hepatitis: A global perspective. J Gastroenterol Hepatol; 2012; 17:155-166.

\footnotetext{
Ngwoke et al., Afro-Egypt J Infect Endem Dis 2019; 9(1):81-86

https://aeji.journals.ekb.eg/

http://mis.zu.edu.eg/ajied/home.aspx
} 
3. Luiz RR, Almeida RM, Almeida RT, de Almeida LM. The relation between anti-hepatitis A virus antibodies and residence water access in Rio de Janeiro, Brazil. Int J Hyg Env Health; 2003; 206:575-82.

4. Bell BP, Kruszon-Moran D, Shapiro CN, Lambert SB., McQuillan GM, Margolis HS. Hepatitis A virus infection in the United States: serologic results from the Third National Health and Nutrition Examination Survey. Vaccine. 2005; 23:5798-806

5. Jacobsen KH, Wiersma ST. Hepatitis A virus seroprevalence by age and world region, 1990 and 2005. Vaccine. 2010; 28 (41): 6653-7

6. Franco E, Giambi C, Ialacci R, Coppola RC, Zanetti AR. Risk groups for hepatitis A virus infection. Vaccine. 2003;21: 2224-2233.

7. WHO. The Global Prevalence of Hepatitis A Virus Infection and Susceptibility: A Systematic Review. 2010. Available from: whqlibdoc.who. int/hq/2010/WHO_IVB_10.01_eng.pdf. 66

8. Jacobsen KH, Koopman JS. Changing hepatitis A seroprevalence: a global review and analysis. Epidemiol Infect; 2004;133: 1005-1022.

9. Wasley A, Fiore A, Bell BP. Hepatitis A in the era of vaccination. Epidemiol Rev. 2006; 28:101-111

10. Ramezani H, Bozorgi SH, Nooranipour M, Mostajeri A, Kargar-Fard H, Molaverdikhani S, et al. Prevalence and risk factors of hepatitis A among blood donors in Qazvin, Central Iran. Singapore Med J. 2011; 52(2): 107-115
11. Ikobah MJ, Henry CO, Emmanuel EE, Jacob JU. Seroprevalence and Predictors of Hepatitis A infection in Nigeria. Pan Afr Med J. 2015; 20:120

12. Ayoola EA. Antibody to Hepatitis A virus in Healthy Nigerians. J Nat Med Assoc. 1982; 74(5): 465-468.

13. David OO, Oyebode TA, Itunu O, Adeolu SO. High seroprevalence of asymptomatic viral haemoparasites among prospective blood donors in Nigeria. Asian Pacific J Trop Med. 2015; 9(7) $658-661$.

14. Hadler SC. Global impact of hepatitis A infection: changing patterns. Viral Hep \& Liver Dis. 1991; 14-19.

15. Okara GC, Hassan S, Obeagu EI. Hepatitis A virus infection among apparently healthy Nigerian Subjects. Journal of Biomedical Science. 2017; 6-2.

16. Jacobsen KH. Wiersma, ST. Hepatitis A virus seroprevalence by age and world region, 1990 and 2005. Vaccine. 2010; 28 (41): 6653-7

17. Colak D, Ogunc D, Gunseren F, Velipasaoglu S, Aktekin MR, Gultekin M. Seroprevalence of antibodies to hepatitis $\mathrm{A}$ and $\mathrm{E}$ viruses in peadiatric age group in Turkey. Acta Microbiolog Immunol Hunga. 2002; 49(1): 93 - 97

18. Gomes MA, Ferreira AS, Da Silva AA, De Souza EL. Hepatitis A: Seroprevalence and Associated risk factors among school children of Sao Lius (MA), Brazil. Brazilian J Epidemiol. 2011; 14(4): $548-555$. 